\title{
Investigating the Risk Preventive and Mitigative Methods used in Gauteng, South Africa: Evidence from Contractors
}

\author{
Nazeem Ansary ${ }^{1}$ and Berenger Yembi Renault ${ }^{2}$
}

\begin{abstract}
This study sought to investigate the effectiveness of risk management methods used in construction projects according to contractor's perspective. Literature search and questionnaire surveys were carried out, and a total of thirteen risk management actions were identified which were further categorized into two groups of preventive and mitigative actions. Research findings identified subjective judgment to produce a proper programme and production of a proper schedule as mostly used actions to manage risks in the first group. Furthermore, close supervision, increase the working hours and coordinate closely with subcontractors were the most used actions to manage risks in the latter group. The results of this study would considerably boost the understanding of risk management actions and also assist contractors in handling various risks faced by the industry.
\end{abstract}

Keywords-construction, contractors, preventive and mitigative actions, South Africa.

\section{Introduction}

All human ventures bring in uncertainty and risk. It is agreed that risk is extreme in the business sector than other sectors. Every entrepreneurial act and a business decision are associated with risk. Risk is an occurrence that has a degree of obscurity and can either be positive or negative. A positive risk is a convenient opportunity, while a negative risk is a threat and hence inconvenient [1]. The more convenient and less convenient risks imply progressive and negative outcomes respectively. However, the construction (CI) faces fewer random risks, but these may have adverse consequences for a time, such as increase cost, time overruns, and low-quality work. The factors leading to such an outcome include planning, design, and construction intricacy as well as the presence of countless interest groups and material resources [2]. Concerning risk negative impacts, [3] clarified that individuals dislike risk and that each party in the $\mathrm{CI}$ is risk averse; consequently, RM becomes significant in eliminating or reducing risk through the various processes of RM.

Berenger Yembi Renault

University of Johannesburg

South Africa

Nazeem Ansary

University of Johannesburg

South Africa
[4] stated that RM has various complicated dimensions relating to the $\mathrm{CI}$, with results that go beyond its direct physical detriment to the financial and cultural processes, and even the way society functions. According to [5], all construction projects are hazardous by nature due to their configuration, financial and organisational arrangements, and technology and resource demands; hence, RM in construction projects is dynamic rather than stagnant. [6] argue that it is crucial for the industry to minimise these risks and uncertainties so as to unearth the impact thereof to determine which part of the project is more expose to risk and less feasible.

Managing risks is an important issue in the planning and management of any business endeavor. Regrettably, the construction industry seems to lack the capacity to identify, analyse and assess risks associated with construction activities, and that is why this research is important, as it aims to investigate preventive and mitigative actions or practices of risk management as perceived by contractors in the Gauteng province of South Africa. Preventive actions are used to avoid and reduce risks at the early stage of project construction whereas mitigative actions are used to mitigate risk impact or likelihood.

\section{Literature Review}

\section{A. Risk Management}

Throughout the world, the construction industry (CI) has changed rapidly over the past decade; enterprises are now confronted with more risk and uncertainty than in the past. Clients are more likely to engage in litigation when things go wrong. Risk in construction has attracted a lot of attention due to time and cost overruns associated with construction projects. Consequently, risk can be described as an uncertain event or condition that, if it occurs, has a positive or negative effect on a project objective [7]. [8] defined risk as the exposure to loss, gain, or the probability of occurrence of loss or gain multiplied by its magnitude.

There is no inclusive study enlightening the causes of risks among construction enterprises; furthermore, studies addressing the matter have attempted to identify the symptoms rather than causes. Many researchers have strived in their studies to establish the causes of threats [7] and categorize the risks in the CI [9].

Various studies have scrutinized the issue of risk management of construction projects. [10] identified, 
scrutinized and assessed the process of risk identification. [11] identified the risks usually faced by construction firms operating in a foreign country. [12] identified the risks that are specific to construction in developing countries arguing that investors should bear the exchange and interest rate risks.

Some variations of the risk management process have been proposed. [13], for example, suggested a process consisting of two main phases: risk assessment, which encompass identification, analysis, and prioritization, and risk control which includes risk resolution, risk management planning, risk resolution and risk monitoring planning, tracking and corrective actions. [14] identified risk management approach as a multiphase 'risk analysis' which covers identification, evaluation, control and management of risks. [15] defined risk management is a set of processes concerned with conducting risk management planning, risk identification, risk analysis, response planning, and monitoring and control on a project. [16] suggested three ways of responding to risk in projects; they are as follows:

Avoidance: consists of eliminating a specific threat, usually by eliminating the cause. The project management team can only eliminate specific risk events.

Mitigation: reducing the expected monetary value at risk events by reducing the probability of occurrence, reducing the event risk value, or both.

Acceptance: entails accepting the consequences. Acceptance can be active or passive. Active by developing a contingency, passive by accepting a lower profit if some activities overrun.

\section{Research Methodology}

Both secondary and primary data were employed in this study to identify and assess the effectiveness of risk management actions used in construction projects in Gauteng. The secondary data was gathered through a comprehensive related literature review. Various sources were consulter of the review including accredited academic and professional journals, books, internet, theses and dissertations. The primary data, on the other hand, was obtained from a well-structured questionnaire. Measures were taken to ensure validity and reliability of the results of the study. In developing the questionnaire, survey items were embraced from preceding studies, wherever possible, to enhance validity. The questionnaire was pilot-tested with construction professionals before the main study, to ensure simplicity, suitability, readability, understanding and time taken in answering the questions. The revised questionnaires were thereafter distributed to medium to large scale construction companies in the province of Gauteng. These companies were selected from the Contractor's list published by the Construction Industry Development Board (CIDB). The respondents included top management of these companies (mostly directors, partners, project managers and construction managers) who were willing to participate in the research. Based on their positions, education, work experience and professional background, the authors inferred that the respondents had adequate knowledge of risk management as well as the activities associated with construction. The drop-off and collect strategy was adopted to increase response rates, as was used by [17].

The questionnaires consisted of four sections: i) background information to obtain information about the respondent and the company itself; ii) the risk factors identified by literature; iii) management methods which can be used to manage risks; and iv) the risk analysis strategies that can be used to analyse and estimate risk factors impact. A five-point Likert scale was used, and the adopted scale was as follows: 1- Never, 2-Rarely, 3-Sometimes, 4-Often, and 5Always. Data collected were analysed statistically using the Mean Item Score (MIS). The indices were used to determine the relative use and ranking of each item. The ranking made it possible to cross compare the relative importance of the items as perceived by the respondents. The similar approach has been used by some researchers to analyse the data gathered from questionnaire survey [18].

The computation of the relative mean item score (MIS) was calculated from the total of all weighted responses and then relating it to the total responses on a particular aspect. The index of MIS of a particular factor is the sum of the respondents' actual scores (on the 5-point scale) given by all the respondents' as a proportion of the sum of all maximum possible scores on the 5-point scale that all the respondents could give to that criterion. Weighting was assigned to each responses ranging from one to five for the responses of 'Never' to 'Always'. The mean item score (MIS) was calculated for each item as follows;

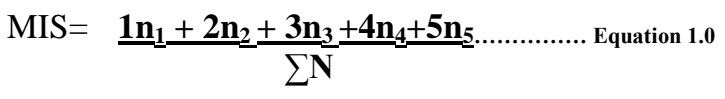

Where: $\mathrm{n} 1=$ Number of respondents for 'Never', $\mathrm{n} 2=$ Number of respondents for 'rarely', $\mathrm{n} 3=$ Number of respondents for 'Sometimes', $\mathrm{n} 4=$ Number of respondents for 'Often', $\mathrm{n} 5=$ Number of respondents for 'Always', $\mathrm{N}=$ Total number of respondents. After mathematical computations, the criteria were then ranked in descending order of their mean item score. After the text edit has been completed, the paper is ready for the template. Duplicate the template file by using the Save As command, and use the naming convention prescribed by your conference for the name of your paper. In this newly created file, highlight all of the contents and import your prepared text file. You are now ready to style your paper; use the scroll down window on the left of the MS Word Formatting toolbar.

\section{Iv. Results and Discussion}

This section of the study presents and describes the views of contractors in the Gauteng province (South Africa) concerning the preventive and mitigative risk management actions presently used by the local industry.

\section{A. Preventive actions}

Figure 1 below represents the seven preventive measures identified by literature. It illustrates that subjective judgment (75\%) and producing a proper schedule $(70.7 \%)$ were the most 
effective risk prevention methods according to respondents. Adjustment for bias risk premium to time estimate was ranked third $(60.7 \%)$. (52.5\%) Of contractors, respondents believe that contractors refer to previous and ongoing similar project for an accurate programme. The other preventives methods such as transferring or sharing of risk to/with other parties (49\%), (35.4\%) of contactors planning alternative methods as stand-by and the use of quantitative analysis techniques for accurate time estimate $(35.3 \%)$ were not recommended by respondents as shown in the figure below.

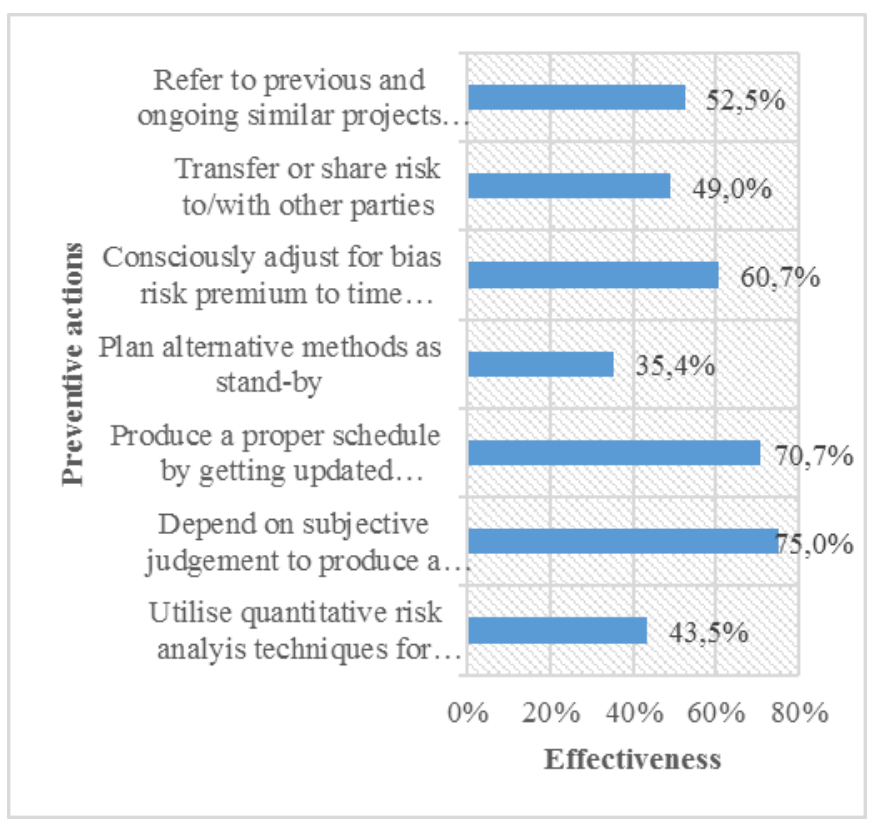

Figure 1. Preventive methods effectiveness

Table 1 below presents the risks preventive actions than can be used to avoid and reduce risks at the early stage of project construction. These were presented according to their Mean Item Score (MIS) and ranked. It is shown that subjective judgment to produce a proper programme was the first preventive action recommended by respondents (MIS=3.27), followed by the production of a proper schedule (MIS=3.04) and adjustment for bias risk premium to time estimate (MIS=2.55). The others preventive methods were not recommended by respondents as illustrated in the table below.

TABLE I. RISK PREVENTIVE METHODS

\begin{tabular}{|l|c|c|}
\hline \multicolumn{1}{|c|}{ Preventive methods } & MIS & RANK \\
\hline $\begin{array}{l}\text { Depend on subjective judgment to produce a proper } \\
\text { programme }\end{array}$ & 3.27 & 1 \\
\hline $\begin{array}{l}\text { Produce a proper schedule by getting updated project } \\
\text { information }\end{array}$ & 3.05 & 2 \\
\hline $\begin{array}{l}\text { Consciously adjust for bias risk premium to time } \\
\text { estimate }\end{array}$ & 2.55 & 3 \\
\hline $\begin{array}{l}\text { Refer to previous and ongoing projects for accurate } \\
\text { programme }\end{array}$ & 2.30 & 4 \\
\hline Transfer or share risk to/with other parties & 2.23 & 5 \\
\hline Plan alternative methods as stand-by & 2.20 & 6 \\
\hline $\begin{array}{l}\text { Utilize quantitative risk analysis techniques for accurate } \\
\text { estimate }\end{array}$ & 2.10 & 7 \\
\hline
\end{tabular}

The survey results in Figure 1, and Table 1 shows that most of the contractors in Gauteng depend on their subjective judgment to produce a proper project programme for the most effective risk preventive actions. Subjective judgment uses the experience acquired from previous or related projects by the decision maker to decide on the probability of risk occurring and the consequences. This preventive risk method may be the most valuable information source when faced with a time constraint to prepare the project programme. Nevertheless, construction being subject to a dynamic environment, the risk task team must always strive to improve their estimates. Even with perfect near estimates, decision making about risk is a difficult task. Therefore, relying only on experience and subjective judgment may not be sufficient, and updated project information should be obtained and applied. As a consequently, contractors should consider getting updated project information and add risk premiums to time estimation in the project planning phase to be effective risk preventive method. This result was predictable since considering such risks' premiums would escalate the priced bid and would accordingly reduce the likelihood of winning the bid due to the highly competitive CI market. Make more accurate time estimation through quantitative risk analyses techniques such as Monte Carlo program was not recommended by the respondents as a preventive efficacious method for reducing the impact of risk. Inadequate knowledge and experience of risk analysis procedures and the complexity of obtaining the probability distribution for risk in practice could be the principal two reasons for such result. Referring to related projects to for accurate program was recommended by the practitioners to be a preventive effective method.

\section{B. Mitigative methods}

Figure 2 presents the mitigative actions identified by literature. The results demonstrate that close supervision $(67.6 \%)$ was seen by the respondents as the first mitigative action followed by increasing the working hours $(61.4 \%)$ and close coordination with subcontractors $(60.7 \%)$, while change the sequence of work $(47.8 \%)$, increase manpower and/or equipment $(37.8 \%)$ and change the construction method $(36.1 \%)$ were not advised by respondents as demonstrated below. 
Proc. of Eighth International Conference On Advances in Civil, Structural and Mechanical Engineering - ACSM 2018

Copyright (C) Institute of Research Engineers and Doctors, USA. All rights reserved.

ISBN: 978-1-63248-154-2 doi: 10.15224/978-1-63248-154-2-28

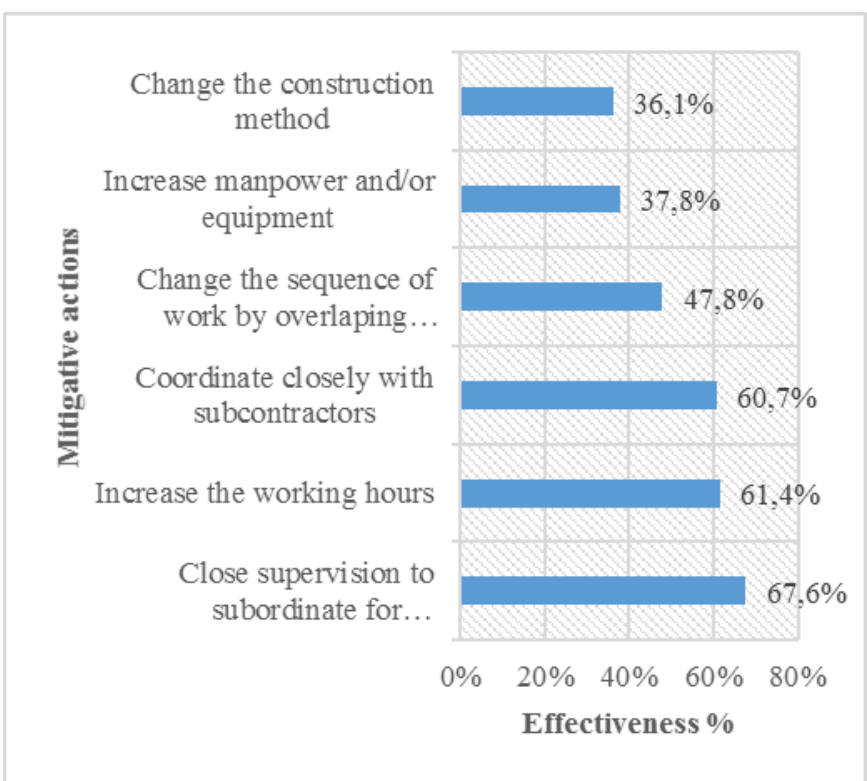

Figure 2. Mitigative methods effectiveness

Table 2 below illustrates mitigative methods that can be used to mitigate risk impact or likelihood. It is indicated that close supervision was the most recommended mitigative method by respondents (MIS=3.78), increase the working hours was ranked second (MIS=3.60) followed by close coordination with subcontractors (MIS=3.55). Respondents seemed not to have recommended the use of other methods as illustrated below.

\section{TABLE II. RISK MITIGATIVE METHODS}

\begin{tabular}{|l|c|c|}
\hline \multicolumn{1}{|c|}{ Mitigative methods } & MIS & RANK \\
\hline $\begin{array}{l}\text { Close supervision to subordinate for minimizing } \\
\text { abortive work }\end{array}$ & 3.78 & 1 \\
\hline Increase the working hours & 3.60 & 2 \\
\hline Coordinate closely with subcontractors & 3.55 & 3 \\
\hline Change the sequence of work by overlapping activities & 2.10 & 4 \\
\hline Increase manpower and/or equipment & 1.68 & 5 \\
\hline Change the construction method & 1.64 & 6 \\
\hline
\end{tabular}

Figure 2 and Table 2 show that close supervision was the first mitigative action recommended by respondents, followed by increasing the working hours which was ranked as second and coordinate closely with subcontractors which were recommended by respondents as the third mitigative action. The results further show that change the construction method was hardly used as mitigative methods, ranked by respondents as the last recommended mitigative method.

This result could mean that the effort driven on the site is one of the most important variables to project progress since construction projects usually require several labor-intensive operations. In fact, deficiency of manpower in subcontractors' enterprises is one of the most serious risks causing project delays. Hence, increasing the work hours usually speeds up progress subject to the availability of materials and managers, physical constraints of the site, and construction sequence.

\section{v. CONCLUSION}

This study sought to assess the effectiveness of risk management actions used in construction projects according to contractor's perspective. A total of thirteen risk management actions were identified which were further categorized into two groups of preventive and mitigative methods. In the preventive group, depending on subjective judgment to produce a proper programme and producing a proper schedule by getting updated project information were identified as the most used methods to manage risks whereas in the mitigative group, close supervision and increase the working hours were identified as the most used mitigative methods to manage risks according to respondents. The results of this study would considerably boost the understanding of risk management actions and also assist contractors in handling various risks faced by the industry. The study recommends that training courses should be offered for engineers and project managers on how to handle and reduce risks in construction projects.

\section{Acknowledgment}

The authors wish to acknowledge their gratitude to all the contractors, in particular the practitioners who actively participated in our survey questionnaire.

\section{References}

[1] Johnson, T. (2008). Project Management Professional (PMP) exam success series: certification exam mannual. Texas: Crosswind Project Management Inc.

[2] Creedy, G.D. (2006). Risk factors leading to cost overrun in the delivery of highway construction projects. PhD Thesis, Queensland University of Technology, Australia, p2.

[3] Laryea, S. (2008). Risk pricing practices in finances, insurance and construction. In: COBRA Research Conference, September 4th -5 th, Dublin Institute of Technology, p2.

[4] Loosemore, M., Raftery, J., Reily, C. \& Higgion, D. (2006). Risk management in projects. London: Routledge

[5] Edwards, P.J. \& Bowen, P.A. (2005). Risk and risk management in construction: a review and future direction for research, engineering, Construction and architectural management, 5(4): 339-349.

[6] Zayed, T. Amer, M. \& Pan, J. (2007). Assessing risk and uncertainty inherent in Chinese highway project using AHP, International journal of project management, 26: 408-419.

[7] Hillson, D. (2002). The Risk Breakdown Structure (RBS) as an aid to effective risk management. In: Proceedings of the 5th European Project Management Conference, PMI Europe, Cannes, France, 19-20 June, 2002, pp. $1-2$

[8] Jaffari, A. (2001). Management of risks, uncertainties and opportunities on projects: time for a fundamental shift, International Journal of Project Management 19, 89-101.

[9] Flanagan, R. (2003). Managing Risk for an Uncertain Future-A Project Management Perspective, School of Construction Management and Engineering, the University of Reading, UK, pp. 23-26.

[10] Bajaj, D., Oluwoye, J. and Lenard, D. (1997). An analysis of contractor's approach to risk identification in New South Wales, Australia, Construction Management and Economics, 15, 363-369

[11] Ramcharran, H. (1998). Obstacles and opportunities in international engineering service, Journal of Management in Engineering, 14 (5), 3846.

[12] Kalayjian, W.H. (2000). Third world markets: anticipating the risks. Civil Engineering, 70 (5), 56-57. 
[13] Raz, T., and Michael, E. (2001). Use and benefits of tools for project risk management, International Journal of Project Management 19, 9-17.

[14] Tummala, V., and Burchett, J. (1999). Applying a risk management process (RPM) to manage cost risk for an EHV transmission line project, International Journal of Project Management 17, 223-235.

[15] Koirala, M.P. (2014). Risks in Housing and Real Estate Construction projects, Journal of the Institute of Engineering, 10(1): 34-44.

[16] PMI. (2008). A Guide to the Project Management Body of Knowledge. Project Management Institute, Newtown Square, PA, pp.301-304.

[17] Agumba, J.N. (2013). A Construction Health and Safety Performance Improvement Model for South African Small and Medium Enterprises. $\mathrm{PhD}$ Thesis, University of Johannesburg, p119.

[18] Le-Hoai, L., Lee, Y. D., and Lee, J. Y. (2008). Delay and cost overruns in Vietnam large construction projects: A comparison with other selected countries, KSCE Journal of Civil Engineering, 12 (6): 367377.

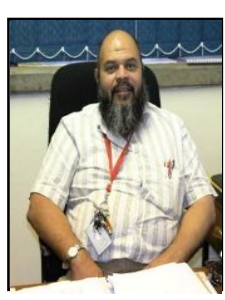

Nazeem Ansary (NHD, BTech QS, MCPM, PrQS, PMAQS, MRICS, MCIOB) holds a National Higher Diploma in Building Surveying and Bachelor's Degree in Quantity Surveying from Cape Peninsula University of Technology, South Africa and Tshwane University of Technology respectively. He received in 2010 his Master's Degree, Master of Construction Project Management from University of New South Wales, Australia. He is a Professional Quantity Surveyor and has many years of working experience in the construction industry and currently working as a senior lecturer and Head of Department Construction Management and Quantity Surveying at the University of Johannesburg, South Africa. He has published several accredited articles in refereed journals and has presented papers in many international conferences all over the world. His main research interests are construction project management, construction management, dispute resolution, and risk management in construction.

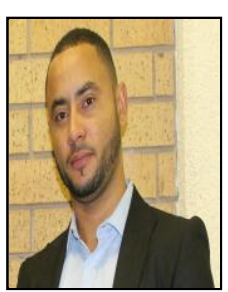

Berenger Y. Renault was born in Gabon on June 26, 1989. He obtained his National Diploma in Construction Management and Quantity Surveying and Bachelor's Degree in Quantity Surveying from University of Johannesburg, South Africa in 2012 and 2014 respectively. He has been a Tutor at the Faculty of Engineering and The Built Environment since 2013. Renault is also a member of the Association of South African Quantity Surveyors. He is currently a Master student at the Department of Construction Management and Quantity Surveying at the University of Johannesburg. His work is animated by an interest in the area of risk management. 